\title{
Papers
}

\section{Relation between headache in childhood and physical and psychiatric symptoms in adulthood: national birth cohort study}

Paul Fearon, Matthew Hotopf

\begin{abstract}
Objective To elucidate the associations between frequent headache and psychosocial factors in childhood and to determine whether such children are at an increased risk of headache, multiple physical symptoms, and psychiatric symptoms in adulthood. Design Population based birth cohort study. Setting General population.

Participants People participating in the national child development study, a population based birth cohort study established in 1958.

Main outcome measures Headache, multiple physical symptoms, and psychiatric morbidity at age 33 . Results Headache in childhood was associated with several psychosocial factors. Prospectively, children with frequent headache had an increased risk in adulthood of headache (odds ratio 2.22, 95\% confidence interval 1.62 to 3.06), multiple physical symptoms (1.75, 1.46 to 2.10$)$, and psychiatric morbidity (1.41, 1.20 to 1.66$)$. The outcomes of headache and multiple physical symptoms were not accounted for by psychiatric morbidity.

Conclusion Children with headache are at an increased risk of recurring headache in adulthood and may complain of other physical and psychiatric symptoms. Strategies for coping with psychosocial adversity in childhood may improve the prognosis in adulthood.
\end{abstract}

\section{Introduction}

Headache is the most common somatic complaint in children. ${ }^{1}$ Although headache is rare before the age of 4 , its prevalence increases throughout childhood reaching a peak at about 13 years of age in both sexes. Estimates of prevalence vary according to age, definition of headache, and method of data collection, but in children of school age as many as $75 \%$ may experience headaches infrequently and about $10 \%$ have recurring headaches. ${ }^{2-4}$

Reports have shown an association between headache in childhood and several psychosocial factors such as depression in the mother, depression in childhood, social disadvantage, and coming from a family with a history of "painful conditions." ${ }^{5-11}$ Other reasons suggest that this complaint has a predominantly psychosocial basis. These include a lack of evidence for organic disease in most patients and a high rate of headache with recurrent abdominal pain, another common somatic complaint of children. ${ }^{12}$ A recent prospective cohort study followed children with recurrent abdominal pain into adulthood..$^{13}$ As adults they had increased physical symptoms, but these were accounted for by the association with increased rates of psychiatric disorder. Additionally, a recent review of functional somatic symptoms in adulthood suggests that these syndromes share many factors, including psychological distress. ${ }^{14}$ It thus seems plausible to speculate that headache in childhood may be associated with an increased risk of both psychological and somatic complaints in adulthood.

Little is known about the long term outcome of headache in childhood. Only one study has followed up children with migraine into adulthood. ${ }^{15}$ Overall, $60 \%$ of those who had had migraine aged between 7 and 15 years were still experiencing migraine attacks 23 years later, but in half of these patients the attacks were neither as frequent nor as severe as in childhood. No study has yet reported in general on the outcome in adulthood of headache in childhood. Most studies have been cross sectional, often utilising populations of participants in clinical settings. Other prospective studies do not extend beyond adolescence. We aimed to elucidate the childhood associations between headache and psychosocial factors in a sample of the general population and to determine whether headache in childhood is associated with an increased risk of physical and psychiatric symptoms in adulthood. ${ }^{12}$

\section{Participants and methods}

The national child development study is an ongoing population based birth cohort study. Its origins lie in the perinatal mortality survey that collected data on the births of 17414 infants born to parents residing in Great Britain between 3 and 9 March 1958, representing $98 \%$ of all births. Five subsequent sweeps of data collection occurred at ages 7, 11, 16, 23, and 33. Information was collected from parents, medical staff, teachers, census records, and the participants themselves, by both postal questionnaire and interview. In 1991, 11407 cohort members were interviewed, represent-

\author{
Institute of \\ Psychiatry and \\ Guy's, King's and St \\ Thomas's School of \\ Medicine, De \\ Crespigny Park, \\ London SE5 8AF \\ Paul Fearon \\ clinical lecturer \\ Matthew Hotopf \\ clinical senior lecturer \\ Correspondence to: \\ P Fearon \\ p.fearon@iop. \\ p.fearon@ \\ BMJ 2001;322:1-6
}


ing $69 \%$ of the target population. The study has received approval from an ethics committee.

\section{Variables in childhood}

Headache-Parents were interviewed when the participants were aged 7 (1965) and 11 (1969). On both occasions they were asked "does your child suffer from frequent headache or migraine?" An ordered categorical variable was created dividing participants into no headache at age 7 or 11, headache at either 7 or 11 only, and headache at both 7 and 11 .

Familial illness-When the participant was aged 7 the presence of any mental illness in a family member (excluding the participant) was inquired after. When the participant was aged 16 his or her parents were asked about their own health; if they had any chronic illness, data about the chronicity of the condition were obtained. From this information a variable was created indicating no illness or illness of 5 years or less and illness of greater than 5 years. This allowed for participants at age 11 or younger who had a chronically ill parent to be distinguished from those after that age whose parents developed illness or who had no chronically ill parent.

Social circumstances-Social class at birth was derived from the father's occupation, determined during the perinatal mortality survey. Two variables were chosen to broadly represent familial and social adversity in early childhood. When the participants were aged 7 information was obtained from interviewing the parents regarding divorce or separation and whether the child had been separated from his or her mother for periods longer than a week before age 7 .

Psychological health-When the participants were aged 7 the Bristol social adjustment guide was completed by their teachers. ${ }^{16}$ The guide rates behaviour at school and consists of 146 items. From these, 12 syndrome scores can be derived, representing aspects of behavioural deviance. Scores for one of these syndromes-depression-were converted into a binary variable denoting "no depression" (score 0-4 of 12) and "some depression" ratings (score $>5$ of 12).

\section{Variables in adulthood}

Multiple physical symptoms-At age 33 (1991) the participants were asked about the specific somatic symptoms of: backache, bad headaches, twitching of the face, head, or shoulders, indigestion, upset stomach, heart racing "like mad," pains in the eyes, rheumatism or fibrositis, and worries about health. Only those who endorsed three or more symptoms were deemed to have multiple symptoms. This definition broadly corresponds to the notion of "abridged somatisation,"17 which is associated with major disability and is probably a clinically relevant level of symptomatology.

Headache - A binary variable denoting those participants who complained of frequent headache at age 33 was created.

Psychological health-When the participants were 33 they completed the 15 item psychological subscale of the malaise inventory, which measures the degree of psychiatric morbidity. ${ }^{18}$ From this information a binary variable denoting the presence of four or more symptoms was derived.

\section{Analytic strategy and methods}

We used STATA release 5 (Stata, College Station, TX) for the management and analysis of all data. We compiled a risk set comprising those participants who had complete data for headache in childhood and associated variables of interest in childhood. We initially explored the relation between headache in childhood and the other variables in childhood including sex and social class, expressed both as percentages and as odds ratios with $95 \%$ confidence intervals. We used the likelihood ratio test for trend to examine associations involving ordered categorical variables.

We performed an unadjusted analysis of the association between both headache in childhood and the other psychosocial variables in childhood and the three outcomes in adulthood using logistic regression analysis. We then constructed a model incorporating all potential confounders for each outcome in adulthood, and we obtained fully adjusted odds ratios and $95 \%$ confidence intervals. We adjusted the models for the outcomes of multiple physical symptoms and headache in adulthood for psychiatric morbidity. We performed a subsidiary analysis excluding headache from the symptom list (but keeping the threshold for outcome definition at three or more symptoms) to give an indication of the extent to which any association found between exposure and multiple physical symptoms might be accounted for by headache in adulthood. Finally, we performed ordinal regression analysis on the fully adjusted models, with the absolute number of physical and psychiatric symptoms separately as outcomes. This technique generates a single odds ratio for ordered categorical outcomes that represents the odds of having the outcome for those with headache compared with those with no headache. ${ }^{19}$

\section{Results}

Follow up and representativeness

Overall, 11407 of the original birth cohort of 17414 participants were interviewed at age 33, representing $69 \%$ of the target population. Despite sample attrition, it has been shown elsewhere that the cohort remains largely representative, although the most disadvantaged groups may be underrepresented at age $23 .{ }^{20}$ Complete data for the childhood variables of interest were available for 9841 participants. Some evidence showed that females were more likely to have complete data at age $7(47 \%(\mathrm{n}=3561)$ of excluded participants versus $49 \%(\mathrm{n}=4837)$ of the risk set), and that those in the manual social class group were less likely to have complete data $(74 \%(\mathrm{n}=4910)$ of excluded participants versus $72 \%(\mathrm{n}=7078)$ of the risk set).

Comparing data at age 7 and 11 showed no difference in the rate of follow up at age 11 according to headache status at age $7(84 \%(\mathrm{n}=682)$ headache at 7 versus $85 \%(\mathrm{n}=7679)$ no headache at $7 ; \chi^{2}=0.58$, $\mathrm{P}=0.45$ ). To explore whether the main exposure was associated with differential censoring at follow up at age 33 we cross tabulated non-participation for all three outcome variables against headache in childhood. We found no evidence of an association between exposure and non-participation for multiple symptoms, headache, or psychiatric morbidity. 


\section{Prevalence of headache in childhood}

We found a prevalence of headache at age 7 of $8.2 \%$ $(\mathrm{n}=811)$, which increased to $15.4 \%(\mathrm{n}=1511)$ by age 11. Most headache occurred in those of a manual social class at both age 7 (manual 75.2\% $(\mathrm{n}=610)$, non-manual 24.8\% $(\mathrm{n}=201) ; \mathrm{P}=0.03)$ and age 11 (manual 77\% $(\mathrm{n}=1163)$, non-manual 23\% $(\mathrm{n}=348)$; $\mathrm{P}<0.001)$.

We found no evidence of a difference in distribution of the sexes at age 7 (male $53.6 \%(n=435)$, female $46.4 \% \quad(\mathrm{n}=376) ; \mathrm{P}=0.1)$, but by age 11 significantly more females were reported to have frequent headache (male $47.8 \%(\mathrm{n}=722)$, female $52.2 \%(\mathrm{n}=789) ; \mathrm{P}=0.01)$. Overall, 3.7\% $(\mathrm{n}=366)$ of the sample had frequent headache at both ages.

\section{Associations between headache and other childhood variables}

Table 1 shows the associations between headache and other variables in childhood. Those with headache were more likely to have a mother with a chronic physical illness that began before the participant was aged 11 , or mental illness in a family member, but there was no significant association with having a father with a chronic physical illness. An association was found between headache in childhood and both depression rating at age 7 and separation from mother for periods of more than one week. Although the odds ratio for the association between exposure and parental divorce or separation was greater than unity, the small proportion of parents separated in this era provided insufficient power to detect a significant relation

\section{Prospective data}

At age 33, 9.3\% $(\mathrm{n}=656)$ of participants had multiple somatic complaints, $14.1 \%(\mathrm{n}=998)$ mentioned headaches, and $13.9 \%(n=972)$ had evidence of psychiatric morbidity. All three outcomes were more common in women and those from a manual social class. Table 2 shows the relations between other psychosocial variables in childhood and the outcomes in adulthood. Overall, these results show a clear relation between psychosocial adversity in childhood and the three outcomes in adulthood.

Table 3 shows the relation between headache in childhood and outcomes in adulthood derived from logistic regression. For all three outcomes there is a significant association with headache in childhood. Controlling for sex and social class, other variables in childhood and adult psychiatric morbidity made little difference to these results. Ordinal regression analysis revealed an overall odds ratio of 1.75 (95\% confidence
Table 1 Relation between psychosocial factors in childhood and both grades of headache in childhood. Values are odds ratios (95\% confidence intervals)

\begin{tabular}{lcc} 
Variable in childhood (age at assessment) & $\begin{array}{c}\text { Headache } \boldsymbol{v} \text { no } \\
\text { headache }\end{array}$ & $\begin{array}{c}\text { Recurrent headache } \boldsymbol{v} \\
\text { no headache }\end{array}$ \\
\hline Moderate or severe depression rating $(7)$ & $1.47(1.15$ to 1.87$)$ & $2.21(1.50$ to 3.27$)$ \\
\hline Parental separation or divorce $(7)$ & $1.17(0.87$ to 1.57$)$ & $1.53(0.93$ to 2.53$)$ \\
\hline Separation from mother for longer than 1 week ever $(7)$ & $1.39(1.24$ to 1.54$)$ & $1.56(1.26$ to 1.93$)$ \\
\hline Chronic maternal illness began aged <11 years $(16)$ & $1.48(1.10$ to 2.01$)$ & $2.39(1.49$ to 3.84$)$ \\
\hline Chronic paternal illness began aged <11 years $(16)$ & $1.23(0.85$ to 1.78$)$ & $1.70(0.91$ to 3.15$)$ \\
\hline Mental illness in family member $(7)$ & $1.69(1.28$ to 2.24$)$ & $2.58(1.65$ to 4.02$)$
\end{tabular}

interval 1.46 to 2.10 ) for the association between headache in childhood and multiple physical symptoms and an odds ratio of 1.41 (1.20 to 1.66) for the association between headache in childhood and psychiatric morbidity.

\section{Discussion}

Children with frequent headache are at an increased risk of headache and multiple physical and psychiatric symptoms in adulthood. This is the first study using prospectively collected population based data, which confirms that children with headache do not simply "grow out" of their somatic complaint and may also "grow into" others. It is unsurprising that the strongest association was found for headache in adulthood. If common childhood somatic symptoms are regarded as signs of underlying psychosocial adversity and learned illness behaviour from parents, then the persistence of the same symptom into adulthood is plausible. Of course some of the participants with headache in childhood will have had migraine, which is known to persist into adulthood in many cases; this may have contributed to the outcome observed here.

\section{Limitations}

Information on variables in childhood relied on reports from the mother. Such proxy reports may not be entirely satisfactory. ${ }^{21}{ }^{22}$ For example, it is possible that mothers with either psychological morbidity or, indeed, multiple physical symptoms are more likely to report physical symptoms in their children. However, these factors were partly, albeit crudely, taken into account in later analysis by controlling for both chronic physical illness in the mother and mental illness in a family member.

Our study had three main outcomes. Participants were classified on the basis of self reported symptoms at only one point in time and were interviewed by nonclinical staff. Additionally, for the outcome of multiple physical symptoms it was not possible to determine

Table 2 Associations between factors in childhood and three outcomes in adulthood at age 33. Values are odds ratios (95\% confidence intervals) unless stated otherwise

\begin{tabular}{|c|c|c|c|c|c|c|}
\hline Variable in childhood (age at assessment) & $\begin{array}{l}\text { Multiple physical } \\
\text { symptoms }\end{array}$ & $P$ value & Headache & $P$ value & Psychiatric morbidity & $P$ value \\
\hline Depression (7) & 1.99 (1.43 to 2.79$)$ & $<0.001$ & 1.37 (1.00 to 1.88$)$ & 0.05 & 1.90 (1.41 to 2.55$)$ & $<0.001$ \\
\hline Parental separation or divorce (7) & 2.31 (1.58 to 3.37$)$ & $<0.001$ & 2.21 (1.58 to 3.08$)$ & 0.001 & 2.11 (1.50 to 2.97$)$ & $<0.001$ \\
\hline $\begin{array}{l}\text { Separation from mother for longer than } 1 \\
\text { week ever (7) }\end{array}$ & $1.32(1.12$ to 1.55$)$ & 0.001 & 1.21 (1.06 to 1.38$)$ & 0.005 & $1.22(1.07$ to 1.40$)$ & 0.004 \\
\hline $\begin{array}{l}\text { Chronic maternal illness began aged }<11 \\
\text { years (16) }\end{array}$ & $1.50(0.98$ to 2.31$)$ & 0.06 & $1.28(0.87$ to 1.88$)$ & 0.20 & 1.78 (1.25 to 2.53$)$ & 0.001 \\
\hline $\begin{array}{l}\text { Chronic paternal illness began aged }<11 \\
\text { years (16) }\end{array}$ & $1.34(0.79$ to 2.27$)$ & 0.28 & 1.76 (1.17 to 2.66$)$ & 0.007 & 1.31 (0.83 to 2.06$)$ & 0.25 \\
\hline Mental illness in family member (7) & 1.86 (1.24 to 2.79$)$ & 0.003 & $1.52(1.05$ to 2.19$)$ & 0.03 & 1.88 (1.32 to 2.67$)$ & $<0.001$ \\
\hline
\end{tabular}


Table 3 Relation between headache in childhood and main outcomes at age 33. Values are odds ratios (95\% confidence intervals) unless stated otherwise. Odds ratios refer to baseline group for each category of headache in childhood. Model 1 controls for sex and social class only, model 2 controls additionally for all variables in childhood, and model 3 controls additionally for all variables in childhood and psychiatric morbidity

\begin{tabular}{|c|c|c|c|c|c|}
\hline & $\begin{array}{c}\text { No of participants } \\
\text { exposed }\end{array}$ & No (\%) of cases & Model 1 & Model 2 & Model 3 \\
\hline \multicolumn{6}{|c|}{ Multiple physical symptoms } \\
\hline No childhood headache & 5631 & $456(8.1)$ & 1.00 & 1.00 & 1.00 \\
\hline Headache & 1153 & $164(14.2)$ & 1.85 (1.52 to 2.24$)$ & 1.77 (1.46 to 2.14$)$ & 1.61 (1.31 to 1.99$)$ \\
\hline \multirow[t]{2}{*}{ Recurrent headache } & 253 & $36(14.2)$ & $1.82(1.26$ to 2.63$)$ & 1.69 (1.17 to 2.45$)$ & 1.67 (1.12 to 2.49$)$ \\
\hline & & & $\chi^{2}=35.9, P<0.001$ & $\chi^{2}=29.2, P<0.001$ & $\chi^{2}=20.2, P<0.001$ \\
\hline \multicolumn{6}{|l|}{ Headache } \\
\hline No childhood headache & 5657 & $690(12.2)$ & 1.00 & 1.00 & 1.00 \\
\hline Headache & 1163 & $247(21.2)$ & 1.92 (1.63 to 2.26) & 1.87 (1.58 to 2.20) & 1.79 (1.51 to 2.12) \\
\hline \multirow[t]{2}{*}{ Recurrent headache } & 253 & $61(24.1)$ & 2.30 (1.69 to 3.12 ) & 2.22 (1.63 to 3.02 ) & 2.22 (1.62 to 3.06$)$ \\
\hline & & & $\chi^{2}=69.4, P<0.001$ & $\chi^{2}=62.9, P<0.001$ & $\chi^{2}=54.6, P<0.001$ \\
\hline \multicolumn{6}{|l|}{ Psychiatric morbidity } \\
\hline No childhood headache & 5615 & $718(12.8)$ & 1.00 & 1.00 & \multirow{4}{*}{ Not applicable } \\
\hline Headache & 1148 & $211(18.4)$ & 1.51 (1.27 to 1.79$)$ & 1.17 (1.00 to .137) & \\
\hline \multirow[t]{2}{*}{ Recurrent headache } & 252 & $43(17.1)$ & 1.38 (0.98 to 1.93$)$ & 1.24 (0.91 to 1.68$)$ & \\
\hline & & & $\chi^{2}=18.2, P<0.001$ & $\chi^{2}=13.6, P<0.001$ & \\
\hline
\end{tabular}

accurately those participants who had genuine organic disease. Ideally hospital records are needed to identify such individuals. It is possible, however, to refer to the findings of other community based studies in which the prevalence of organic disease in participants with physical symptoms has been identified. In one survey, only $10 \%$ of headaches, back pain, and abdominal pain and $18 \%$ of dizziness in participants of all ages were considered to have an organic cause. ${ }^{23}$ Since that study took place in a clinical setting, it is likely that the true prevalence of an organic cause in a young population based sample is lower. Furthermore, it is known that those mentioning multiple rather than single somatic symptoms are less likely to have underlying disease. The population we studied comprised adults at age 33, in whom organic disease is less likely to be a major factor accounting for such symptoms.

We chose a threshold of three or more symptoms somewhat arbitrarily to represent those participants likely to mention multiple somatic complaints in adulthood. Analysis of the data using a cut off-point of four or more symptoms did not, however, substantially alter our findings. Similarly, we chose four or more items endorsed on the malaise inventory a priori to represent those likely to have major psychiatric morbidity. Furthermore, the results of the ordinal regression analysis confirmed a significant association with headache in childhood for both outcomes.

That these children mentioned more physical and psychiatric symptoms in adulthood than those without headache merits consideration. As somatic symptoms in adulthood are associated with psychological factors, one possible explanation is that these physical symptoms represent an aspect of continuing psychological morbidity in this group. However, controlling for adult psychiatric morbidity resulted in a minor change only in this association, suggesting that this outcome may be partly independent of psychiatric morbidity. This contrasts with the literature on the outcome of recurrent abdominal pain in adulthood, in which such children's physical symptoms as adults are explained largely by concurrent psychiatric morbidity. ${ }^{13}$ One reason for this difference may lie in the different method used to ascertain psychiatric data in that study. Psychiatric morbidity was rated by using a more detailed semistructured interview and may therefore have been a more sensitive source than our study. Secondly, although recurrent abdominal pain and headache share many common associations in childhood, they may differ in their trajectory into adulthood. Headache in childhood, although undoubtedly associated with psychosocial adversity in many cases, may nonetheless represent a more stable, specific phenotype than other common childhood symptoms. A further plausible explanation for the increased risk of physical and psychological symptoms in adulthood reported by these individuals is that it may reflect, at least in part, the way in which parents, teachers, and health professionals responded to their distress as children.

The pathway from psychosocial factors and somatic symptoms in childhood to somatic and psychiatric symptoms in adulthood remains unclear and needs further investigation. However, taken together, our findings of an association between both headache in childhood and psychosocial factors and headache in childhood and adult morbidity may have implications for the health of today's children and their future wellbeing. We suggest that the wide range of

\section{What is already known on this topic}

Common somatic symptoms in childhood are associated with psychosocial factors and may increase the risk of physical and psychiatric symptoms in adulthood

No study has yet examined at the general population level the outcome as an adult of headache, the commonest somatic complaint in childhood

\section{What this study adds}

Children who mention headache are more likely to experience psychosocial adversity and to grow up with an excess of both headache and other physical symptoms and psychiatric symptoms 
professionals to whom a child with headache may present (including teachers, school nurses and doctors, general practitioners, paediatricians, neurologists, and child psychiatrists) should consider the possible role of underlying psychosocial factors in the child's symptoms. If such factors are present and amenable to change, it is possible that intervention may reduce the risk of the child developing symptoms as an adult. This may be even more relevant today than when these participants were children in the 1960s. Evidence shows that the prevalence of headache in childhood is increasing steadily in the developed world, ${ }^{24}$ and if this is so there may well be a corresponding increase in somatic and psychiatric symptoms as today's children become adults.

Contributors: PF and MH formulated the hypotheses. PF performed the analysis and undertook the main writing of the paper. MH participated in discussing core ideas, interpreting the results, and revising the final version. PF will act as guarantor for the paper.

Funding: None.

Competing interests: None declared.

1 Egermark-Eriksson I. Prevalence of headache in Swedish schoolchildren. A questionnaire survey. Acta Paediatr 1982;71:135-40.

2 Waters WE. Community sudies of the prevalence of headache. Headache 1970;9:178-86

3 Larsson BS. Somatic complaints and their relationship to depressive symptoms in Swedish adolescents. J Child Psychol Psychiatry 1991;32:82132.

4 Passchier J, Orlebeke JF. Headaches and stress in schoolchildren: an epidemiological study. Cephalgia 1985;5:167-76.

5 Zuckerman B, Stevenson J, Bailey V. Stomachaches and headaches in a community sample of preschool children. Pediatrics 1987;79:677-82

6 Andrasik F, Kabela E, Quinn S, Attanasio V, Blanchard EB, Rosenblum EL. Psychological functioning of children who have recurrent migraine. Pain 1988;34:43-52.
7 Cunningham SJ, McGrath PJ, Ferguson HB, D'Astous JD, Latter J, Goodman JT, et al. Personality and behavioural characteristics in pediatric migraine. Headache 1987;27:16-20.

8 Egger HL, Angold A, Costello EJ. Headaches and psychopathology in children and adolescents. I Am Acad Child Adolesc Psychiatry 1998;37(9):951-8

9 Carlsson J. Prevalence of headache in schoolchildren: relation to family and school factors. Acta Paediatr 1996;85:692-6.

10 Sillanpaa M, Piekkala P, Kero P. Prevalence of headache in preschool age in an unselected child population. Cephalgia 1991;11:239-42.

11 Oster J. Recurrent abdominal pain, headaches and limb pains in children and adolescents. Pediatrics 1972;50:429-36.

12 Borge AIH, Nordhagen R, Moe B, Botten G, Bakketeig LS. Prevalence and persistence of stomach ache and headache among children. Follow-up of a cohort of Norwegian children from 4 to 10 years of age. Acta Paediatr 1994;83:433-7.

13 Hotopf M, Carr S, Mayou R, Wadsworth M, Wesseley S. Why do children have chronic abdominal pain, and what happens to them when they grow up? Population based cohort study. BMJ 1998;316:1196-200.

14 Wessely S, Nimnuan C, Sharpe M. Functional somatic syndromes: one or many? Lancet 1999;354:936-9.

15 Bille B. Migraine in childhood and its prognosis. Cephalgia 1981;1:71-5.

16 Stott DH. The social adjustment of children. London: University of London Press, 1969.

17 Escobar JI, Golding JM, Hough RI, Karno M, Burman MA, Wells KB. Somatisation in the community: relationship to disability and use of services. Am J Public Health 1987;77:837-40.

18 Rutter M, Tizard J, Whitmore K. Education, health and behaviour. London: Longmans, 1970.

19 Scott SC, Goldberg MS, Mayo NE. Statistical assessment of ordinal outcomes in comparative studies. J Clin Epidemiol 1997;50(1):45-55.

20 Power C, Manor O, Fox J. Health and class: the early years. London: Chapman and Hall, 1991.

21 Ecob R, MacIntyre S, West P. Reporting by parents of longstanding illness in their adolescent children. Soc Sci Med 1993;36(8):1017-22

22 Sweeting H, West P. Health at age11: reports from schoolchildren and their parents. Arch Dis Child 1998;78:427-34.

23 Kroenke K, Mangelsdorff AD. Common symptoms in ambulatory care: incidence, evaluation, therapy and outcome. Am J Med 1989;86:262-6.

24 Sillanpaa M, Anttila P. Increasing prevalence of headache in 7-year-old schoolchildren. Headache 1996;36(8):466-70.

(Accepted 20 February 2001) 